Número DOI: 10.1590/permusi2015b3218

RESENHA

\title{
Resenha do livro Romani routes: cultural politics and Balkan music in diaspora, de Carol Silverman
}

\section{Review of the book "Romani routes: cultural politics and Balkan music in diaspora" by Carol Silverman}

Jorge Linemburg 1

1 Universidade do Estado de Santa Catarina, Florianópolis, Santa Catarina, Brasil.
jlinemburg@hotmail.com

SILVERMAN, Carol. Romani routes: cultural politics and Balkan music in diaspora. Oxford University Press, 2012, 398 p. R\$182,70.

Data de recebimento: 03/12/2014

Data de aprovação final: 20/09/2015

O livro Romani Routes, de Carol Silverman, foi lançado em momento oportuno, considerando-se a grande atenção que a academia tem voltado para questões concernentes ao povo romani ${ }^{1}$ e a popularidade que sua música vem desfrutando nos últimos quinze anos, especialmente, na Europa Ocidental e nos EUA. Embora o interesse pelos romanis seja crescente, a atmosfera xenofóbica estigmatizada que paira sobre este povo nos diversos países que habitam não foi extinta. Tal questão, de grande importância, é colocada pela autora já no início do livro: os "romanis são paradoxalmente venerados como músicos, mas desprezados como povo" (Roma are paradoxically revered as musicians and reviled as people; SILVERMAN, 2012, p.3). ${ }^{1}$ Optou-se, nesta resenha, pela utilização do termo/adjetivo "romani" ao invés de "cigano" (tradução do inglês "Gypsy"), que
apesar de ser utilizado por alguns membros da própria cultura, carrega conotações pejorativas (SILVERMAN, 2012, p. 295). 
Romani Routes é um estudo que combina a abordagem transnacional à etnografia, de acordo com a própria autora. Este trabalho representa o resultado de mais de trinta anos de envolvimento com a cultura e a música balcânicas (Macedônia e Bulgária) e com imigrantes romanis macedônicos nos EUA e na Europa Ocidental, nos papéis de pesquisadora, professora, ativista e performer (http://pages.uoregon.edu/anthro/people/faculty/corefaculty/).

O livro contém treze capítulos, organizados em quatro partes: I - Introduction, II - Music in Diasporic Homes, III - Music, States, and Markets e IV-Musicians in Transit. Uma página na rede foi criada para acompanhar o conteúdo do livro: www.oup.com/us/romaniroutes. Nela, são encontrados exemplos de vídeos, gravações de áudio, fotografias, além de textos suplementares. Para acessá-la são necessários um nome de usuário e uma senha, ambos fornecidos no corpo do livro.

No capítulo 1, Silverman apresenta o livro e as questões abordadas, além de um panorama geral dos romanis e da diáspora, com origem no norte da Índia, entre os anos 1100-1300, elucidando seu estabelecimento nos Bálcãs. A partir daí, novos movimentos migratórios foram iniciados, em meados do século XIX, rumo à Europa Ocidental e, na década de 1960, aos EUA. A autora confronta a popularidade da música romani com estes fluxos migratórios. Ao longo do livro, procura dissolver a visão simplista de que a música romani tem um início "puro" ou "autêntico" no contexto de comunidades delimitadas e que, somente pelo contato com mercados não-ciganos, se torna híbrida. Uma mistura de necessidade econômica, marginalização, formação de identidade e exibição simbólica, através da música compõem o assunto do livro.

No capítulo seguinte, a antropóloga explora a música como uma profissão histórica, com mais de 600 anos entre os romanis, e demonstra como a opinião acadêmica sobre essa música, no papel de corruptora/mantenedora de tradição, oscila entre extremos. Em alguns países, como Espanha, Hungria e Rússia, a música associada aos romanis tornou-se um emblema nacional. A autora chama a atenção para a inexistência de uma música romani universal ou pan-europeia, dizendo que a música dos romanis representa um verdadeiro mosaico cultural. Conjuntos formados por uma ou duas zurli (plural de zurla, instrumento 
de sopro, de diâmetro cônico e palheta dupla) e um ou dois tapani (plural de tapan, tambor cilíndrico de pele dos dois lados) parece ser uma das únicas formações musicais virtualmente monopolizadas pelos romanis do sul dos Bálcãs. Os tocadores destes instrumentos são sempre indivíduos do sexo masculino e seu aprendizado se dá no seio do ambiente familiar. Outros contextos musicais citados pela autora para os romanis dos Bálcãs são o das bandas de metais, mais recentes, e dos treinadores de ursos e macacos. Características apontadas como íntimas ao fazer musical dos romanis são a improvisação e a grande capacidade de se adaptar a novas influências. O čoček é o gênero musical romani mais característico nos Bálcãs, associado à dança solo de mesmo nome, amplamente difundido e encontrado em diversas outras regiões do globo onde a diáspora se estabeleceu, como na Europa Ocidental, EUA e Austrália. Este gênero utiliza escalas derivadas da música turca (makams), mas também inclui escalas maiores e menores ocidentais. Os čočeks normalmente apresentam seções com temas pré-compostos e outras de demonstração de virtuosismo, com improvisação e exploração rítmica sobre essas escalas. Ritmicamente, esta música possui muitas variedades e o livro apresenta uma figura com quatorze delas (SILVERMAN, 2012, p.29).

No terceiro capítulo, a autora discute como os romanis têm absorvido a visão da academia de questões levantadas a seu respeito, como a diáspora, transnacionalismo, hibridação e o caráter cosmopolita. O problema de se tentar identificar a diáspora romani é querer unificar e apontar uma única origem a um povo que está constituído de diversas culturas. Segundo Silverman, o conceito de transnacionalidade aplica-se facilmente ao povo romani porque deixa de lado a ideia de terra-natal e se foca no povo e nas comunidades, uma característica presente no discurso dos romanis imigrantes. A discriminação parece ser algumas vezes a única característica que unifica este povo e é justamente isto o que eles desejam eliminar. O movimento de direitos dos romanis criou uma série de símbolos nacionais: o rótulo unificador (roma), uma narrativa singular de origem indiana, o holocausto como símbolo de opressão, uma bandeira, uma linguagem literária e um hino. A sua história de exclusão fez com que eles se reunissem em torno dela para construir um movimento étnico pan-romani. O rótulo é amplamente empregado por aqueles que falam a língua romani (equivalente a metade da população romani), mas rejeitado por outros. Alguns ativistas utilizam informações dúbias para afirmar as origens dos romanis como sendo indianas, além das 
menos questionáveis como a língua. Eles afirmam que certas escalas musicais e passos de dança têm origem na Índia. Nos anos 1970, diversos músicos romanis da Macedônia e da Sérvia incorporaram em seus repertórios canções e melodias indianas, transformando alguns desses temas em čočeks. A autora aborda como o hino, Dželem Dželem (Eu viajei e viajei), revela uma rede complexa das políticas de identidade e demonstra como os romanis escolhem representar a si mesmos. Este capítulo discute, ainda, como que, apesar da exclusão, os romanis construíram seus próprios símbolos de herança como parte de um processo estratégico dentro da política europeia.

As famílias romanis são transnacionais, permanecendo em contato com os parentes através de ligações telefônicas, enviando músicas e vídeos de casamentos pelos correios, assim como os recebendo em casa. É muito comum fazerem vídeos de seu cotidiano e enviarem a parentes distantes. Quando documentam as suas celebrações, focam-se em dois aspectos particulares: as pessoas e a música. Normalmente, os romanis da Macedônia possuem parentes na Europa Ocidental, EUA e Austrália. No capítulo 4, a autora explora como as comunidades macedônicas consolidam seus laços com a Macedônia e outros locais da diáspora, através do casamento, da língua e do ritual, tudo isto determinado pela música e pela dança. A separação de familiares, que migram para trabalhar, é narrada nas canções, sempre com muita dor. De modo interessante, os textos se referem frequentemente a familiares e nem tanto ao lugar de que procedem. Diversos músicos profissionais imigrantes em Nova York combinam a música a outros trabalhos diários, como zeladores e entregadores. Neste capítulo, ainda são relatados casos de músicos macedônicos que se recusaram a tocar em grandes concertos para outras etnias, quando descobriram que foram referenciados como romani nas notas de programa.

As celebrações são a "cola" que mantêm os romanis ligados às suas comunidades e famílias. Nestes eventos, normalmente, pode-se ver a presença de música e dança. Nos EUA, os ritos de passagem (casamentos, batizados e circuncisões) são mais festejados que as datas comemorativas do calendário. A noiva é o foco do ritual nos casamentos, com a maioria dos costumes deste evento e dos textos das canções referenciando-se a ela. Música e dança são requeridos nos casamentos romanis balcânicos e da diáspora. A música é de domínio dos homens, enquanto a dança, das mulheres. Os casamentos duram em torno de cinco dias. A 
procissão da hena acontece nas ruas, acompanhada de música alta, tocada por uma banda de zurla e tapan, enquanto que outros eventos de dança utilizam uma orquestra de casamento moderna. Tipicamente, os únicos homens presentes na cerimônia da hena são os músicos contratados. Igranka (festa da dança) é a parte do casamento em que se formam as linhas de dança que serpenteiam ao redor de dançarinas solistas. Os instrumentos são acústicos e a música tocada é o čoček. A contratação de músicos de outras localidades é uma marca de status. Existem algumas canções típicas do ritual de entregar a noiva à família do noivo. Num casamento realizado na comunidade macedônica romani de Belmont, Nova York, relatado pela autora, dois músicos (um clarinetista e um cantor) eram amigos do pai da noiva e viajaram da Alemanha, onde moravam, para tocar. Além do prestígio deste fato, os músicos trazem e levam informações e presentes. Nesta ocasião, tocaram com músicos locais um repertório conhecido por todos, uma vez que a Macedônia é a referência. Outra parte importante dos casamentos é a procissão do casal de noivos pelo salão do banquete, passando por todas as mesas, que pode levar várias horas e é acompanhado por canções lentas, geralmente em turco. Existem muitos músicos profissionais romanis macedônicos na área de Nova York, todos homens, pois não é bem-visto pela comunidade mulheres trabalharem profissionalmente com música e realizar performances para estranhos. Os músicos contratados são sempre de comunidades romanis, pois eles têm que conhecer o repertório específico para cada momento da celebração. Um cachê é negociado, mas os músicos tocam com expectativas de receber gorjetas extras. Como os casamentos são esporádicos, os músicos acabam arranjando empregos diários, além de tocar em festas e casas noturnas de outras etnias. Como também têm de dominar o repertório da outra etnia, acabam contratando um cantor conhecedor deste repertório. No último tópico deste capítulo, Belmont Musicians, a autora cita diversos músicos e seus meios de atuação dentro e fora das comunidades romanis, tocando repertórios tradicionais e fundindo diferentes gêneros, incluindo jazz.

O capítulo 6 compara e discute a dança čoček em diversos contextos, enfatizando as dimensões estilística, social e de poder em relação à marginalidade dos romanis numa sociedade mais ampla e a posição ambivalente das mulheres, extremamente mal-vistas quando atuam profissionalmente dentro e, principalmente, fora de suas comunidades. Por outro lado, estes problemas são mitigados pelo reconhecimento e alto valor dado à dança como uma forma de arte feminina. Até a década de 1970, a dança era algo separado 
sexualmente, as mulheres se encontravam umas nas casas das outras com uma tocadora de dajre (espécie de pandeiro) e uma cantora. Nos casamentos, as mulheres são obrigadas a dançar por horas, incentivadas por familiares. O capítulo também traça historicamente o gênero desde as épocas do Império Otomano até a atualidade, explora a maneira pela qual as mulheres negociam performances de dança dentro das comunidades da diáspora romani e como a dança profissional se torna um capital simbólico a ser negociado no mercado comercial. Compara performances de dança romani em diversos grupos para demonstrar a variedade de estilos representacionais e o uso de estereótipos.

No capítulo 7, a autora investiga as relações performativas complexas entre os romanis e o estado socialista através da análise da política dos conjuntos de zurna e tupan e do gênero "música de casamento" (svatbarska muzika) búlgara. A música folclórica se tornou um símbolo politizado da nação búlgara, com suas delimitações sendo cuidadosamente estabelecidas e a música romani, ficando de fora, não era tocada nos festivais, por conjuntos, ou nas escolas. Diferente da Bulgária socialista, onde foram regulados e, posteriormente, proibidos, na Macedônia, esses músicos eram constantemente contratados por rádios e conjuntos estatais. Em 1984, a zurna foi banida oficialmente de todos os contextos, na Bulgária, devido à sua origem turca. A autora participou de um casamento em 1980, numa região em que esses instrumentos haviam sido banidos, mas músicos foram contratados para tocá-los. Na edição de 1985 do Festival Pirin Pee, músicos romanis que tocavam os instrumentos chegaram até o festival e tocaram em local mais isolado, num exemplo de resistência. As proibições duraram até 1989 e, devido à resistência dos músicos e dos contratantes, as bandas emergiram como uma tradição vital. De 1984 a 1989, o čoček, muito difundido entre os romanis e os turcos, também foi banido da gravadora oficial do estado.

O gênero "música de casamento" experimentou grande fama nas décadas de 1970 e 1980. Como os romanis eram os grandes inovadores, controvérsias se formaram ao redor deste gênero. Entre os puristas, era rotulado como "kitsch" e "corrupto", mas tinha o maior número de fãs. Proibido na década de 1980 pelo governo socialista, sua ausência nas mídias estatais promoveu seu sucesso nos meios alternativos. Com raízes em conjuntos urbanos que datam do século XIX, compostos em sua maior parte por músicos romanis, o gênero se cristalizou nas décadas de 1960 e 1970. O que o define é uma combinação entre sua instrumentação, 
repertório e estilo. Consiste de clarinete, saxofone, acordeão, guitarra e baixo elétricos, bateria e um vocalista. Na década de 1980, foram adicionados sintetizadores, substituindo, eventualmente, a percussão e os instrumentos elétricos. Em alguns casos, violino, trompete, ou instrumentos tradicionais eram incluídos. O repertório está dividido em duas categorias principais: música búlgara e música romani (čoček). Também citam temas famosos no meio das peças, como clássicos de rock, "Vôo do besouro", "Can can" etc. Acima de tudo, a capacidade de improvisar é valorizada pelos músicos e pela audiência. A música de casamento era inextricavelmente ligada a grandes eventos e comum na Bulgária entre todas as etnicidades. O grande fenômeno é Ivo Papazov, clarinetista de ancestralidade turca e romani. Ivo inovou nas harmonias, novos acompanhamentos e uma sonoridade mais moderna para sua época, com mais improvisação. As bandas misturam membros romanis e búlgaros. Quando mulheres participam, são cantoras e normalmente esposas de algum dos músicos. A tradição desta música é estritamente oral, com os músicos ciganos aprendendo dentro de suas famílias. Os cachês eram altos, com uma banda ganhando, naquela época, para tocar num casamento até cinco vezes mais o que um operário num mês de trabalho. As críticas mais comuns a esta música, por parte de acadêmicos e outros puristas, era de que ela incorporava elementos estrangeiros, deste modo, não retendo a pureza da música folclórica búlgara. Foram desenvolvidas técnicas pelos músicos e contratantes para evitar a prisão durante a performance nos eventos. Pessoas ficavam no alto das casas avistando eventuais batidas policiais. Uma das formas era se esconder, mas caso não houvesse tempo, os músicos convertiam čočeks em música búlgara, que era permitida.

O capítulo 8 lida com a "música de casamento" no período pós-socialista, na Bulgária, sua relação ao contexto ascendente do capitalismo, novos mercados e configurações políticas e uma onda crescente de xenofobia. Na década de 1990, o gênero experimentou grande prestígio internacionalmente, mas, na Bulgária, sofreu desventuras econômicas. A banda de Ivo Papazov, Trakiya, realizou turnês nos EUA, entre 1989 e 1992, organizadas pelo produtor musical Joe Boyd. Elas aconteceram na época em que a World Music se tornou uma categoria viável de mercado, com o próprio Boyd sendo uma das pessoas que cunhou o termo nas Ilhas Britânicas. Apesar das novas liberdades quanto ao repertório, o que tocar e misturar, a situação econômica abalada do país também se refletiu na procura pelos músicos. Os casamentos não duravam mais que uma tarde ou uma noite na década de 1990, 
com a música ficando a cargo de um $D J$. Nesta mesma década, algumas famílias romanis e turcas eram as únicas a manter música ao vivo, não por serem mais ricos, mas porque a música é essencial para eles nesses eventos. Uma preocupação que se tornou comum no póssocialismo foram os direitos autorais e a exploração das gravadoras. Papazov diz que a época socialista era bem melhor de trabalho do que na democracia. Os músicos de casamento culpam a chalga (discutida no capítulo seguinte) pela decaída no prestígio da música de casamento.

A chalga, discutida no capítulo 9, surgiu no início da década de 1990 como resultado da fusão de estilos folclóricos pan-balcânicos com a música pop romani, turca e de casamento. É um fenômeno que gerou milhões de fãs. Como o funk brasileiro, está fora da mídia convencional e costuma ser associado a "classes baixas", tendo reputação de gênero "nãocivilizado". A palavra chalga é de origem turca (instrumento, ou música instrumental), mas na Bulgária assumiu a designação de música folclórica/pop ou etno/pop, vocal, altamente influenciada por estilos romanis. O čoček é o ritmo predominante, normalmente em fórmulas de compasso 2/4 e 4/4, mas também em 7/8 e 9/8. O čoček, compartilhado pelos romanis e pelos turcos, marca simbolicamente o gênero como oriental ou do leste. Entretanto, esta associação se dá também pela visão fantasiada que se tem do oriente, sempre relacionado à sensualidade, neste contexto. O termo folk, tanto em sérvio quanto no búlgaro, refere-se ao que é novo, mas de alguma forma ligado ao local, enquanto que narodno concerne ao tradicional ou autêntico. A chalga e a música romani em geral não são incluídas no último verbete. As denominações turbofolk (Sérvia) e pop/folk (Bulgária) escapam a rigidez do tradicional, mas mantém uma conexão ao local e simultaneamente dão um toque de modernidade. A autora afirma que o ritmo de čoček é o que há de realmente folk na chalga. O čoček é o ritmo característico, então, de três gêneros: música romani, música de casamento e chalga. Devido à conotação negativa do termo chalga, as companhias utilizam outras terminologias, como pop/folk, folk/pop, new folk, contemporary folk, mas raramente chalga. Silverman traz, também, uma análise de como elementos romanis e da diáspora são representados em videoclipes, nas imagens, no texto das canções, nas vestimentas, nos instrumentos ou mesmo nos ritmos utilizados. Existe uma indústria da chalga, liderada pela Payner Company, que além de gravar e produzir os artistas, possui uma estação de rádio, canais de televisão e um negócio de cirurgia plástica, ditando as tendências e o mainstream 
da chalga. Há outros ramos menos visados da chalga: romani, turco e da música e casamento. No início dos anos 2000, os músicos desapareceram de cena, com as estrelas, especialmente femininas e vestindo pouca roupa, ao som de sintetizadores dominando o visual da chalga mainstream. Azis e Sofi Marinova são as estrelas romanis mais proeminentes da chalga. De modo geral, a música romani foi apropriada pela chalga e os músicos excluídos. Uma grande exceção é Azis, um fenômeno que atrai milhares de fãs especialmente pelas quebras de tabus em seus videoclipes.

O capítulo 10 explora a história de vida de Esma Redžepova, eleita a "Rainha da música romani”, na Índia, em 1976. Esma é uma superstar macedônica no contexto do multiculturalismo iugoslavo e atua como ponte entre os romanis e os não-romanis. Seu sucesso deve-se, em parte, à ação marqueteira de seu marido e mentor, o acordeonista e arranjador Stevo Teodosievski, de origem não-romani. Ela resistiu a normas de gênero, uma vez que mulheres que escolhem se tornar cantoras profissionais, não são bem-vistas entre os romanis. Além disto, casou-se com um cônjuge de fora de sua etnia, o que resultou em repulsa dentro de sua comunidade. Este fato foi contornado, após ter se tornado uma artista de reconhecimento internacional. Foi a primeira musicista romani dos Bálcãs (entre homens e mulheres) a alcançar sucesso comercial no mundo não-romani, abrindo portas para outras mulheres e romanis em geral. Desde o começo de sua carreira, deixou explícita sua origem, através do uso pioneiro da língua, dança, música e roupas romanis. Em seu primeiro álbum, aparece o termo Gypsy Music. Canta, entretanto, em diversos idiomas iugoslavos, de países balcânicos vizinhos e mesmo de outras etnias distantes (russa, hebraica, alemã e hindi). O traço internacional mais forte em sua carreia, segundo Silverman, parece ser sua ligação com a Índia.

No capítulo 11, é tratada a maneira pela qual o instrumentista Yuri Yunakov utiliza a performance musical como estratégia de política de identidade pessoal. Emigrou em 1994 para os EUA e toca regularmente para diversas comunidades: romanis, macedônicos, turcos, armênios, albaneses, búlgaros e estadounidenses. Natural de uma região búlgara, onde se fala turco, Haskovo, localizada a 50 km de distância das fronteiras com a Turquia e a Grécia, Yuri sempre se identificou como búlgaro turco. Entretanto, na Bulgária, era visto como romani pelos búlgaros não-romanis. Somente após a sua ida para os EUA é que começou a 
se identificar com a cultura romani. De acordo com a autora, o músico rejeita alguns estereótipos ciganos, como o de "ladrões sujos", mas aceita outros, como o de "geneticamente talentosos" e de "exoticidde".

O termo Gypsy music se transformou numa mercadoria e num símbolo recorrente no discurso sobre "autenticidade" e "exótico", em contextos como os dos festivais de World music e em turnês. O capítulo 12 discute a música romani como World music, ou quando romanis locais atingem fama internacional: como o local se torna global. Também examina o mercado e consumo desta música e como ela delineia as relações entre produtores e diretores de festivais, audiência e imprensa (com dinheiro para investir) e os músicos romanis, normalmente membros de grupos marginalizados. Entretanto, ao invés de vê-los como simples vítimas de manipulação, a autora explora como esses músicos administram e negociam suas representações, mapeando a relação de como os realizadores e produtores de festivais de música romani atuam, a audiência, a imprensa e os músicos romanis. Há um debate entre autenticidade e a emergência de novas fusões, tal como o Gypsy Punk, e como estas tendências revelam estratégias de marqueteiros e performers. Após 1989, ou póssocialismo, numerosos festivais e turnês de música romani têm sido organizados pelo continente europeu. A autora aponta os filmes Latcho Drom, de Tony Gatlif, e diversos de Emir Kusturica como marcos de uma verdadeira loucura pela música cigana, coincidente com este período. Faz uma crítica ao primeiro filme, apontando-o como responsável pelo estabelecimento de diversos estereótipos dos romanis. Os organizadores de festivais e a imprensa sempre vendem a música sob os rótulos de "autenticidade" e "exótico", aproveitando-se da valorização corrente na Europa moderna do "tradicionalismo". Outro tropo bastante vendido é o da caravana: que os ciganos teriam emigrado de maneira quase linear da Índia à Espanha. Dentro do chamado movimento Gypsy Punk, as roupas coloridas e a atmosfera circense são apontadas como os elementos "ciganos" dentro da performance, havendo pouca ou nenhuma relação com a música romani, em si, o que a autora trata como um exemplo de "apropriação".

O último capítulo conecta as tendências dos capítulos anteriores para abordar colaboração, apropriação e movimento transnacional de música em relação a matrizes políticas e econômicas. A autora enumera uma série de exemplos de colaboração entre músicos/bandas 
romanis e não-romanis. Também discute como o músico Goran Bregović, que se tornou internacionalmente famoso pelas trilhas sonoras dos filmes Time of the Gypsies e Underground, do diretor Emir Kusturica, passou de colaborador a apropriador da música romani, visto como um "ladrão" entre muitos músicos romanis. Às bandas do movimento Gypsy Punk sobrepõem-se a um mundo mercadológico em expansão de $D J$ 's, responsáveis pela mixagem de música romani, que se apresentam para grandes multidões em diversas cidades no oeste europeu e EUA. Fala ainda sobre a importância do filme Borat!... na divulgação da música romani para o público diverso e de algumas associações entre esta música e as imagens, que desagradaram a muitos membros da comunidade romani.

Trata-se de um trabalho de grande fôlego que discute questões centrais, como diáspora, identidade, gênero, autenticidade e tradição, entre outras. No entanto, os grupos que a autora aborda simbolizam apenas uma parcela do povo romani. Devido a sua ampla distribuição pelo globo, os romanis acabaram desenvolvendo costumes e hábitos muito heterogêneos, sempre influenciados pelos locais que habitam, o que a autora comenta no livro. No que diz respeito à sua música, uma evidência desta enorme diversidade é exemplificada na coletânea de três volumes World of Gypsies, compilada por Horst Tubbesing. Ela contém registros musicais romanis de diversos países europeus, além da Bulgária e Macedônia (também presentes): Hungria, Polônia, República Theca, Romênia, Sérvia, Albânia, Grécia, Alemanha, Espanha e França; e de outros continentes: Turquia, Rússia, Rajastão, Egito e Marrocos.

Nesse contexto, é válido discorrer a respeito de estudos sobre música romani no Brasil; extremamente escassos, por sinal. O folclorista potiguar Luís da Câmara Cascudo traz no verbete "ciganos", em seu Dicionário do folclore brasileiro, alguma informação sobre o assunto, especialmente em relação aos instrumentos utilizados:

\footnotetext{
Apesar de renome secular de músicos e bailadores, pouca influência deixam no Brasil na espécie. Aproveitam versos populares, traduzindo-os para o calão ou geringonça e cantando-os ao som do violão, violino, o instrumento clássico, e atualmente a sanfona, indispensável em seus acampamentos (CASCUDO, 2012, p.207).
}

O folclorista cita uma relação de estudiosos e seus respectivos trabalhos sobre a cultura cigana no Brasil. Dentre estes, ressalta-se aqui o Cancioneiro dos Ciganos: Poesia Popular 
dos Ciganos da Cidade Nova, publicado em 1885, da autoria de Mello Morais Filho, no qual o autor apresenta uma enorme quantidade de versos recolhidos. A respeito da música cigana, fala o seguinte: “A sua musica é monotona ( $\mathrm{sic}$ ), a sua voz plangente e nasal, a sua poesia pura como uma hóstia, mas humida (sic) de pranto como um sudario (sic)!” (MORAIS FILHO, 1885, p.x).

No Dicionário musical brasileiro, Mário de Andrade não acrescenta muitas informações, encontrando-se apenas referência à dança denominada "cigana" ou "gitana", que segundo o autor, é uma dança muito popular em Portugal, registrada já no séc. XVI, mas com uso também no Brasil. Naquele país, os dançarinos bailavam ao som de um tambor (ANDRADE, 1989, p.243). Assim, aponta-se a abertura de uma interessante lacuna para pesquisa etnomusicológica no Brasil.

O pesquisador e presidente da Embaixada Cigana do Brasil - Phralipen Romani, Nicolas Ramanush, está preparando um livro que trará uma síntese sobre a história da música e da dança ciganas, abordando-as também no Brasil, com previsão de lançamento até o final do ano (RAMANUSH, 2014).

O trabalho de Carol Silverman, pelo caráter fortemente etnográfico, ausência de interpretações de viés musicológico e presença, por outro lado, de discussões extensas de temas centrais da antropologia, acaba tratando a música como o ponto de partida, não o foco. Isto resulta numa aproximação à abordagem antropológica musical de Alan P. Merriam, da música na cultura (MERRIAM, 1964).

\section{Referências}

1. ANDRADE, M. (1989). Dicionário Musical Brasileiro. Belo Horizonte: Ed. Itatiaia.

2. CASCUDO, L. C. (2012). Dicionário do folclore brasileiro. $12^{\mathrm{a}}$ Ed. São Paulo: Global. 3. MORAES FILHO, M. (1985). Cancioneiro dos Ciganos: Poesia Popular dos Ciganos da Cidade Nova. Rio de Janeiro: B.L. 
4. MERRIAM, A. P. (1964). The anthropology of music. Evanston: Northwestern University Press.

5. RAMANUSH, N. (11 de março de 2014). Mensagem pessoal. Mensagem recebida por $<$ jlinemburg@hotmail.com>.

6. SILVERMAN, C. (2012). Romani routes: cultural politics and Balkan music in diaspora. Oxford University Press.

7. TUBBESING, H. (2000). World of Gypsies. Vols. 1, 2 e 3. ARC Music, East Grinstead.

Nota sobre o autor:

Jorge Linemburg é mestre em música pela UDESC - linha de pesquisa musicologia/etnomusicologia -, mesma instituição na qual desenvolve pesquisa sobre rabecas no Brasil, sob orientação do professor Doutor Luiz Henrique Fiaminghi, desde 2010. Estudou violino com Marcelo Brandão Melo e teve aulas de viola de arco com Keroll Weidner, Marcelo Lemos da Silva e Emerson di Biaggi. Integrou o naipe de violas da Orquestra de Cordas da Ilha de 2010 a 2014, tendo feito parte, na mesma função, de outras orquestras da cidade de Florianópolis: Orquestra de Câmara UNISUL (2009), Orquestra Sinfônica de Santa Catarina - OSSCA (2009-2010) e Orquestra UDESC (2011). Paralelamente, atua como violinista e rabequista no grupo de câmara Sexteto Clariô, desde 2012. 